\title{
Los exiliados argentinos y las luchas por la justicia $(1976-1981)^{1}$
}

\author{
Silvina Jensen ${ }^{2}$
}

\begin{abstract}
Resumen
El artículo analiza los modos en que los desterrados argentinos apelaron a la estrategia jurídica como forma de resistencia antidictatorial, partiendo de la denuncia del funcionamiento del Poder Judicial y del reclamo de respeto de los derechos y garantías procesales fundamentales, hasta llegar a proponer un «Núremberg» en el que fueran tramitadas las violaciones a los derechos humanos que se estaban produciendo en el país.

El trabajo sostiene que en la coyuntura delimitada por la aprobación de las leyes dictatoriales sobre «desaparecidos» (septiembre 1979), la publicación del informe de la visita a la Argentina de la Comisión Interamericana de Derechos Humanos de la Organización de Estados Americanos (abril 1980) y las alternativas políticas que rodearon la conmemoración del $5^{\circ}$ aniversario del golpe de Estado (marzo 1981), los exiliados comenzaron a vislumbrar a la justicia (nacional o internacional) como un horizonte -difuso pero creíble- en el que buscar castigo para los culpables de delitos contra la vida, la libertad y la integridad de los argentinos y en particular para los responsables del crimen más abyecto del Estado terrorista: la desaparición forzada de personas.
\end{abstract}

\begin{abstract}
The article analyzes the manners in which the Argentine exiles appealed to the juridical strategy as form of antidictatorial resistance, departing from the denunciation of the functioning of the Judicial Power and the claim of respect of the rights and procedural fundamental guarantees, up to managing to propose a «Núremberg» in which the violations were proceeded to the human rights that were taking place in the country.

The work supports that in the conjuncture delimited by the approval of the dictatorial laws on «missing persons» (September, 1979), the publication of the report of the visit to the Argentina of the Inter-American Commission of Human Rights of the Organization of American States (April, 1980) and the political alternatives that surrounded commemoration of the 5 th anniversary of the coup d'état (March 24, 1981), the exiles began to glimpse to the justice (national or international) as a horizon - diffuse but credibly - in that to look for punishment for the perpetrators of crimes against the life, the freedom and the integrity of the argentinians and especially for those responsible for most abject crime of the terrorist State: the enforced disappearance of persons.
\end{abstract}

1 Trabajo recibido el 18/09/2017. Aceptado el 8/12/2017.

${ }^{2}$ Magister en Historia Moderna y Contemporánea y Doctora en Historia por la Universidad Autónoma de Barcelona. Docente del Departamento de Humanidades de la Universidad Nacional del Sur. Investigadora Independiente del Consejo Nacional de Investigaciones Científicas y Técnicas. Contacto: silvinajensenmail@gmail.com 
ESTUDIOS - $\mathrm{N}^{\circ} 38$ (Julio-Diciembre 2017) 13-30

Palabras clave: exiliados argentinos - última dictadura militar - luchas por la justicia debido proceso - Núremberg
Keywords: argentine exiles - last military dictatorship - justice fights - due process Núremberg

\section{Introducción}

En la Argentina, la historiografía sobre la justicia en el pasado reciente ha ido modelando un complejo mosaico de temas y problemas en el que, junto a los estudios sobre el funcionamiento de la Corte Suprema y los tribunales inferiores entre 1976-1983, se acumula una más profusa bibliografía sobre el Juicio a las Juntas militares, interrogado desde la teoría jurídica, desde su cobertura mediática y su impacto en el espacio público; en el contexto de las políticas sociales de elaboración memorial del pasado violento y como fundamento del nuevo Estado de derecho y de la nueva cultura democrática; como hito en el procesamiento de las violaciones a los Derechos Humanos a escala global y como referente de los procesos de justicia transicional; y también como parte de las luchas del movimiento de Derechos Humanos en el ámbito nacional y continental. ${ }^{3}$

Este artículo reconoce una deuda con un conjunto de trabajos que a lo largo de tres décadas y desde contextos, preguntas, enfoques y perspectivas disciplinarias diversas, vienen echando luz sobre las complejas, dinámicas y no siempre lineales relaciones entre activismo humanitario y justicia en la Argentina dictatorial y postdictatorial. ${ }^{4} \mathrm{Y}$ parte del reconocimiento de una cierta área de vacancia con respecto a algunos actores sociales y escenarios geográficos en ese proceso de vertebración de la lucha humanitaria y la exigencia de justicia punitiva durante la última dictadura militar.

\footnotetext{
${ }^{3}$ Sin ninguna pretensión de exhaustividad cabe mencionar entre los principales referentes del campo a Camarasa, Felice y González, (1985); Groisman, (1987); Acuña et al, (1995); Gónzalez Bombal, (1995); Ciancaglini y Granovsky, (1995); Nino (1997); Malamud Goti, (2000); Feld, (2002); Vezzetti, (2002); Jelin, (2006); Crenzel, (2008, 2015); Sarrabayrouse Oliveira, (2011); Sikkink, (2011); Villalta, (2012); Bohoslavsky, (2015); Galante, (2014); Gandulfo, (2014, 2015).

${ }^{4}$ Especialmente González Bombal y Sondereguer, (1987); Leis, (1989); Jelin, (1995, 2015); Quiroga (1996); Crenzel, (2008, 2015); Galante, (2014); Gandulfo, (2014); Feld y Franco, (2015).
} 
Por un lado constato una cierta invisibilización académica de los exiliados como actores que contribuyeron desde sus prácticas resistenciales y en sus debates políticos y teóricos en la contemporaneidad dictatorial no solo a desvelar la nueva la institucionalidad fundada en la fuerza de las armas y a denunciar la ausencia de garantías judiciales dentro del país bajo imperio del Estado de sitio. También en el camino de buscar el amparo de la comunidad internacional frente a la vulneración sistemática de derechos, garantías y libertades, comenzaron a imaginar a la justicia como un espacio donde exigir cuentas a aquellos que estaban perpetrando violaciones a los Derechos Humanos en la Argentina. En ese contexto, los exiliados avanzaron tanto en la tipificación de un delito de nuevo cuño como la desaparición forzada de personas, como en el debate acerca del modelo de juicio posible, apelando a las experiencias preexistentes en la jurisdicción penal internacional (Núremberg y Tokio) y en diálogo con juristas, teóricos europeos del derecho y con familiares de víctimas de otros países del subcontinente americano.

En esta línea, el artículo pretende echar luz sobre una coyuntura cuyos hitos más salientes fueron la aprobación de las leyes dictatoriales que regulaban el tema de «jubilaciones, pensiones y prestaciones no contributivas» de los «ausentes del lugar de su residencia o domicilio» ${ }^{5} \mathrm{y}$ habilitaban por vía express a certificar el fallecimiento presunto de los «desaparecidos»; ${ }^{6}$ la visita de la Comisión Interamericana de Derechos Humanos (CIDH) a la Argentina (6-20/9/1979) y la publicación de su informe (abril 1980); la constitución del Grupo de Trabajo sobre Desapariciones Forzadas e Involuntarias de Personas de la Comisión de Derechos Humanos de Naciones Unidas (29/2/1980); la celebración del ler Coloquio Internacional sobre Desaparición Forzada de Personas (París, 31/1-1/2/1981) y del ler y 2do Congreso Latinoamericano de Familiares de Desaparecidos organizados por la Fundación Latinoamericana por los Derechos Humanos y el Desarrollo Social (San José de Costa Rica, enero 1981, Caracas, noviembre 1981); y la conmemora-

\footnotetext{
${ }^{5}$ La Ley 22.062 (5/9/1979) pretendía «regularizar la situación que aflige a un número de familias argentinas, motivada por la ausencia prolongada y el destino de algunos de sus integrantes, como consecuencia de los graves eventos que afrontó nuestro país en el pasado reciente» (BORA, 12/9/1979).

${ }^{6}$ La Ley 22.068 (12/9/1979) establecía que «podría declararse el fallecimiento presunto de la persona cuya desaparición del lugar de su domicilio o residencia $[. .$.$] hubiese sido feha-$ cientemente denunciada entre el 6/11/1974, fecha de declaración del Estado de sitio [...] y la fecha de la presente ley». CIDH, (1980).
} 
ción en diferentes capitales de la diáspora del $5^{\circ}$ aniversario del golpe de Estado (Madrid, Barcelona, México, París).

Atendiendo a esta coyuntura, me propongo reponer algunos de los debates que protagonizaron los exiliados argentinos en el horizonte de la justicia punitiva, debates en los que comenzaron a plantear de forma imprecisa pero no por ello menos insistente y extensa, cuestiones tales como: el tipo de delito a perseguir, los marcos normativos disponibles para su prosecución en el ámbito nacional e internacional o la necesidad de dar forma a nuevos instrumentos jurídicos y las opciones de aplicarlos de forma retroactiva, los diferentes niveles de responsabilidad penal, el tipo de castigo imaginado (justicia retributiva, justicia preventiva, justicia revolucionaria, justicia burguesa), el ámbito de realización de un futuro proceso penal (fuera o dentro de las fronteras de la Argentina), y su distancia temporal (futuro próximo o lejano).

Por otro lado verifico que la historiografía argentina parece acordar que fue en la etapa post Malvinas y sobre todo desde la normalización institucional de 1983 cuando los tribunales argentinos fueron imponiéndose como el «escenario privilegiado para procesar las graves violaciones a los Derechos Humanos cometidos en la segunda mitad de la década del '70». ${ }^{7}$

En este relato, se asume que durante buena parte del «Proceso de Reorganización Nacional», los ejes fundamentales de la lucha del movimiento humanitario fueron la búsqueda de la verdad y la denuncia pública acerca de las violaciones perpetradas por el Estado, sus agentes e instituciones represivas, por un lado; y la solidaridad y apoyo a los familiares de las víctimas en términos de asistencia jurídica, psicológica, material y hasta afectiva, por el otro. Se afirma que cuando los organismos humanitarios se planteaban recurrir a la justicia no lo hacían entendiendo por tal la prosecución de los culpables de violaciones a los Derechos Humanos, sino apelando a los tribunales de la dictadura, exigiéndoles verdad sobre el destino de los secuestrados y su eventual liberación (en particular desde el instrumento jurídico del habeas corpus).

Como afirma Jelin, «toda demanda de justicia consiste en la exigencia de la retribución de un equilibrio dañado» ${ }^{8} \mathrm{y}$ en los primeros años de la dictadura, los organismos no estaban en condiciones de reconocer la verdadera naturaleza y dimensión de las desapariciones forzadas, ni

${ }^{7}$ Crenzel, (2015): 81.

${ }^{8}$ Jelin, (1995): 119. 
de identificar con precisión la autoría represiva. En tal sentido, el camino hacia el «juicio y castigo» supuso superar un conjunto de obstáculos y no fue sino hasta la derrota militar en Malvinas y en el contexto del «show del horror», cuando las condiciones para un enjuiciamiento a los culpables fueron tomando forma dentro del país.

Así en el relato historiográfico surgen dos puntos de inflexión en el camino hacia la definición de la justicia como el espacio privilegiado donde tramitar el pasado de violencia extrema y hacia la instalación del «Juicio y castigo a todos los culpables» como consigna hegemónica del movimiento humanitario. Por un lado, la etapa post derrota militar en Malvinas y sobre todo durante el primer año de la postdictadura, cuando se articula la estrategia de sometimiento de los perpetradores de crímenes horrendos a la justicia penal. ${ }^{9} \mathrm{Y}$, por el otro, un escenario previo y aún más abierto que el anterior, cuando a impulso de un «organismo externo», la $\mathrm{CIDH}$, se enuncia «la primera propuesta orientada a la formulación de una política de juzgamiento por las violaciones a los derechos humanos» y todo ello gracias a que, como afirma Galante, la comisión de la OEA ofreció un primer informe sistemático del «entramado de la red represiva». ${ }^{10}$

Partiendo de estos desarrollos historiográficos, pero asumiendo la necesidad de pensar al movimiento humanitario argentino en perspectiva transnacional ${ }^{11}$-esto es, atendiendo a la circulación de personas, ideas y prácticas más allá de las fronteras nacionales y desde la posibilidad de reconstruir las redes efectivas en las que se sostuvo su trabajo de denuncia durante la dictadura-, este trabajo se propone: 1) atender a los diferentes modos en que los exiliados -sobre todo aquellos grupos con experticia en el derecho- entendieron la estrategia jurídica como forma de resistencia (en su pluralidad de prácticas, sentidos y alcances) frente al despliegue represivo del Estado dictatorial; y 2) repensar en forma comprehensiva y situada cómo los exiliados argentinos fueron imaginando y trabajando en forma temprana y colaborativa con actores del universo humanitario del interior y del espacio público transnacional (organismos internacionales (OEA, NNUU) y organizaciones no gubernamentales (Amnistía Internacional, FundaLatin, Comisión Internacional de Juristas, Justicia y Paz, Pax Romana, etc.), es pos de algún tipo de «Núremberg» para la Argentina. En este plano, intentaré mostrar que si el

${ }^{9}$ Crenzel, (2015).

${ }^{10}$ Galante, (2014): 39.

11 Alonso, (2015). 
Informe de la CIDH (abril 1980) cristalizó la demanda de «investigación» $\mathrm{y}$ «sanción» a las «autoridades públicas y a sus agentes» imputadas en secuestros, torturas y muertes, y en tal sentido puede considerarse la primera propuesta clara de juzgamiento a los responsables de las violaciones a los Derechos Humanos perpetradas en el país; una cierta idea de justicia punitiva (bajo la forma de «ajuste» o «rendición de cuentas»; «síndrome», «bandera» o «fantasma» de Núremberg) también formaba parte del horizonte de acción antidictatorial de los exiliados. Desde esta lógica, me propongo hacer foco en algunas de las ideas y estrategias discutidas en diferentes eventos y geografías del exilio en los que se comenzó a plantear la posibilidad de un futuro juicio a los responsables de la violencia represiva que sufrían los argentinos. Sin que estos derroteros jurídicos exiliares del mediodía del «Proceso» (1979-1981) puedan asumirse como caminos lineales que condujeron al «Juicio a las Juntas», considero que admiten ser pensados como parte del mismo proceso, aunque no necesaria ni plenamente en sus alternativas exitosas, sino quizás y más bien en sus vías inconclusas y largamente postergadas.

\section{Los exiliados y la denuncia del sistema judicial dictatorial}

La denuncia fue un eje prioritario en el trabajo de las organizaciones de exiliados. En ese marco, el primer desafío fue mostrar que mientras la Junta afirmaba protagonizar un «proceso de reorganización nacional» en base al «accionar de las instituciones constitucionales revitalizadas» y a la «vigencia plena del orden jurídico y social» estaba operando la más completa «cesación del Estado de derecho», ${ }^{12}$ en tanto la Constitución Nacional era apenas una «referencia formal» ${ }^{13}$ y todos los derechos contemplados por los instrumentos internacionales del sistema humanitario eran vulnerados en forma cotidiana y sistemática.

En la denuncia de esta «nueva la institucionalidad fundada en la fuerza de las armas» ${ }^{14} \mathrm{y}$ en el reclamo por la plena vigencia de la Consti-

\footnotetext{
12 CADHU, (2014): 49.

13 Tribunal Permanente de los Pueblos. «Resolución sobre la situación de los Derechos Humanos en la Argentina». Ginebra, 3-4/5/1980. Colección CADHU, Caja 19: Informes y declaraciones, Archivo Nacional de la Memoria, Buenos Aires.

${ }^{14}$ CADHU. «La ruptura de la legalidad constitucional en Argentina, 1983». Colección CADHU, Caja 28: Cuadernillos/Volantes y Catálogos, Archivo Nacional de la Memoria, Buenos Aires.
} 
tución Nacional, el trabajo de los exiliados hizo foco en el funcionamiento del Poder Judicial, en el comportamiento de los jueces de la Corte Suprema y de los tribunales inferiores y en las dificultades para el ejercicio de la profesión para los abogados dedicados a la defensa de presos políticos y gremiales.

En particular para aquellas organizaciones del exilio con una fuerte impronta jurídica en su composición o perfil ${ }^{15}$ desnudar la perversidad del sistema judicial argentino, mostrar los límites que encerraba la apelación a los tribunales de la Nación para la protección de la integridad de los individuos y revelar cuáles eran los derechos constitucionales y garantías procesales conculcados por los militares (asistencia jurídica y defensa en juicio, proceso justo en tribunales imparciales y ante jueces naturales, presunción de inocencia, la no retroactividad de las normas penales, la presunción de inocencia, derecho de opción y de amparo, habeas corpus) ${ }^{16}$ fueron modos específicos de ejercicio de la resistencia antidictatorial. Modos que se sustentaban en la urgencia de explicar que más allá de la declarada «vocación legalista» de la Junta; ${ }^{17}$ tras el golpe, el Estado de derecho había sido arrasado y los argentinos vivían en total desamparo porque estaban privados de toda forma de justicia.

En este contexto, el trabajo de los exiliados en relación con el sistema judicial argentino transitó por dos vías complementarias, que en algún sentido resultaban contradictorias, aunque ya habían sido ensayadas en el país durante la «Revolución Argentina», incluso por los mismos actores que ahora las desplegaban en el destierro. ${ }^{18}$ Por un lado, la de

\footnotetext{
${ }^{15}$ Por caso la Comisión Argentina de Derechos Humanos (CADHU), pero también organizaciones sectoriales del exilio con perfil jurídico (Abogados Argentinos Exiliados) y otras de perfil político partidario abierto (Comité de Solidaridad con el Pueblo ArgentinoCOSPA y el Comité de Apoyo al Pueblo Argentino de Madrid (CALPA) del que surgiría el Centro Argentino de Eduardo Duhalde y Gustavo Roca) o de referencia humanitaria y antidictatorial (Comisión de Solidaridad de Familiares de Desaparecidos, Muertos y Presos Políticos-COSOFAM), que trabajaban en el asesoramiento jurídico de familiares de víctimas, exigiendo que los detenidos sean sometidos a juicio en los tribunales del país y que fueran respetadas las garantías procesales del reo. Asimismo, denunciaban la falta de independencia del Poder Judicial, la funcionalidad de jueces y juristas con los objetivos represivos del Estado pretoriano y la cantidad de abogados defensistas muertos, «desaparecidos», encarcelados o exiliados.

${ }^{16}$ CADHU, 2014: 39-52.

17 CADHU, 2014: 51.

${ }^{18}$ Basta recordar que entre los integrantes de la primitiva CADHU figuraban los abogados Mario Hernández, Mario Amaya, Daniel Antokoletz, Roberto Sinigaglia y Marta Taboada, antiguos militantes de la Asociación Gremial de Abogados y de otros agrupamientos de
} 
denunciar en forma abierta en qué medida la nueva normativa represiva y las instituciones del Estado terrorista generaban desamparo jurídico. Por el otro, promover la utilización de las instituciones de la «justicia burguesa» por parte de represaliados y familiares, exigiendo la aplicación estricta de instrumentos jurídicos como el habeas corpus o la «opción de salir del país» que no solo habían sido limitados, vaciados de sentido y convertidos en vías muertas de reclamo por el destino y la libertad de los detenidos, sino que también habían sido suspendidos por tiempo indeterminado, luego restablecidos y reglamentados al punto de convertir lo que era un derecho constitucional en una simple petición ciudadana condicionada a la arbitrariedad de la Junta. Curiosamente, mientras los exiliados denunciaban que la Constitución era una referencia meramente formal, apelaban a ella y a la justicia que ella y la normativa de excepción de la Junta habilitaban para tratar de conseguir la libertad de los detenidos sin causa ni proceso, la mejora de las condiciones de detención de los presos «legales» o la localización de los que se encontraban en situación de desaparición. En la Navidad de 1977, COSOFAM Madrid en solidaridad con los Familiares de Argentina recurría al pueblo y a las instituciones del Estado español para fortalecer su reclamo a la Junta militar de una «Navidad en Paz» consecuencia de una «Navidad con Justicia». En el petitorio reclamaba por «la aparición de los desaparecidos y la liberación de los detenidos por razones políticas sin causa ni proceso y/o la opción para salir del país» y por «el juzgamiento de acuerdo a la Constitución Nacional y las leyes de los que tuvieran causa y /o proceSO». ${ }^{19}$

\section{Los exiliados y la apelación a los instrumentos del Derecho Interna- cional Humanitario}

En la década de 1970 «el discurso de los derechos humanos estaba en pleno proceso de emergencia política» ${ }^{20}$ y la invocación al Derecho Humanitario como forma de obtener protección internacional frente a

letrados comprometidos con la defensa de presos políticos y gremiales y/o claramente identificados con las organizaciones revolucionarias. Sobre el tema, véase: Bohoslavsky, (2015) y Chama, (2016).

${ }^{19}$ COSOFAM Madrid. «La paz se construye con la justicia», diciembre 1977, en: Amorós (2011): 126.

${ }^{20}$ Franco, (2011): 98. 
las violaciones y atropellos a la dignidad de hombres y mujeres ocurridas en el territorio de un Estado no constituía una herramienta habitual.

Si bien en el contexto de la segunda posguerra mundial y como consecuencia de los procesos de violencia política y racial extremos fue aprobándose un conjunto de instrumentos internacionales humanitarios generales y específicos, para finales de la década del 1970 y principios del 1980 apenas unos pocos estaban en vigencia. Iban lentamente recibiendo la adhesión y ratificación de $\operatorname{los} \operatorname{Estados}^{21}$ y su eficacia para incidir en la protección de derechos y libertades vulnerados no solo se revelaba como dudosa, sino que existía una amplia consciencia de que su naturaleza abría sobre todo el camino más para condenas morales o políticas de los Estados y menos para sanciones penales (esto era especialmente cierto para las declaraciones y resoluciones de NNUU o de la OEA).

$\mathrm{Si}$, como afirma Marina Franco, en estos años poco a poco los Derechos Humanos fueron incorporándose como «criterio importante en la agenda política y en las relaciones exteriores de muchos países», ${ }^{22}$ cabe analizar cómo se posicionaron los exiliados argentinos de cara a la lucha contra la dictadura y qué uso hicieron del derecho Internacional Humanitario.

En líneas generales puede afirmarse que los exiliados argentinos percibieron muy rápidamente que si en el orden interno la invocación a la Constitución Nacional podía ser una herramienta para defender a los compatriotas cuyos derechos eran pisoteados por la violencia represiva del Estado, en el orden internacional ese Derecho Humanitario no solo podía ser útil para traducir un caso nacional de violaciones a los Derechos Humanos a escala global, multiplicando así las posibilidades de la concitar solidaridad de organizaciones internacionales de carácter universal (NNUU) o regional (OEA) y de organizaciones no gubernamentales, sino también para resignificar los alcances de su estrategia jurídica de denuncia antidictatorial.

\footnotetext{
${ }^{21}$ Más allá de que como explicaba COSOFAM en el Coloquio de París, «la Nación Argentina es miembro de la OEA y de la ONU, con lo cual el gobierno argentino debe acatar obligatoriamente lo estipulado por las cartas fundamentales de esas dos entidades», la Convención Americana sobre Derechos Humanos no fue ratificada sino hasta 1984. COSOFAM. «Desamparo y Solidaridad. La búsqueda delos detenidos desaparecidos en la Argentina», París, 31/1-1/2/1981, en: Amorós, (2011): 343.

${ }^{22}$ Franco, (2011): 99.
} 
De hecho, fue en la búsqueda de expandir las garantías judiciales cercenadas en el espacio público nacional y de incidir con más eficacia en la protección de los derechos y libertades básicas de sus compatriotas que los exiliados descubrieron el potencial de este novedoso pensamiento jurídico tramado por los instrumentos del Derecho Internacional Humanitario. ${ }^{23}$

Pero desde fines de los años 1970 y principios de los 1980, los exiliados también comenzaron a visualizar que más allá de las condenas políticas, simbólicas y morales ${ }^{24}$-algunas de las cuales se tradujeron en castigos financieros y suspensión de ayuda militar- que Argentina iba acumulando desde diferentes actores de la comunidad internacional, ${ }^{25}$ esta normativa -con sus instrumentos vigentes o desde la articulación de otros nuevos- podía dar cauce a cierta pretensión de justicia punitiva que comenzaba a debatirse en las comunidades del destierro.

En este ámbito, una muy abierta e imprecisa idea de un «Núremberg» comenzó a colonizar el horizonte de expectativas de los desterrados. Se trataba de apelar a las instituciones del orden internacional y a su entramado jurídico humanitario -desde su alcance y con sus limitaciones- para, por un lado, lograr tipificar los delitos cometidos en Argentina como crímenes internacionales y contra la Humanidad y, por el otro, para comenzar a trabajar en la vía de la persecución y castigo no solo de los Estados sino de los individuos que hubieran vulnerado los derechos y garantías protegidos por este vasto conjunto de declaraciones, convenciones y pactos del Derecho Humanitario Internacional.

\footnotetext{
${ }^{23}$ Varios instrumentos internacionales daban cabida a la protección del desamparo jurídico de los ciudadanos argentinos, insistentemente denunciado desde el destierro. Así era habitual que los exiliados recurrieran a la Declaración Americana de Derechos y Deberes del Hombre para denunciar la vulneración del derecho de justicia (Art XVIII) y al proceso regular (Art XXVI) o a la Convención Americana sobre Derechos Humanos para criticar el incumplimiento de principios y garantías procesales básicas, a saber: la no retroactividad de las normas penales, la aplicación de la ley penal más benévola, la presunción de inocencia, el derecho a un juicio imparcial y por tribunales competentes e independientes y el derecho a la asistencia profesional y técnica del reo (Arts. 8 y 9).

${ }^{24}$ La primera denuncia del exilio que alcanzó repercusión mundial y por la cual se canceló toda ayuda militar a la dictadura argentina, fue la presentación de dos integrantes de la CADHU (Roca y Garzón Maceda) en la Sub Comisión de Organismos Internacionales de la Comisión de Relaciones Internacionales del Congreso de los EE.UU. Garzón Maceda, (2006): 233-270.

25 CADHU, (2014): 172.
} 


\section{Los exiliados y los debates en torno a un «Núremberg» para los res- ponsables de las desapariciones forzadas de personas en Argentina}

Mientras exploraban el potencial del espacio público internacional y apelaban a su arsenal normativo para reclamar protección jurídica frente a las violaciones a los Derechos Humanos, los exiliados argentinos empezaron a imaginar un horizonte de justicia punitiva mediante el aprovechamiento de ciertos instrumentos del Derecho Internacional Humanitario -por caso las Convenciones de Ginebra de 1949 que introdujeron la jurisdicción universal ${ }^{26}$ y sobre todo el Protocolo Adicional no I (1977) y la Convención sobre la Imprescriptibilidad de los Crímenes de Guerra y Crimes Against HumanityCrímenes contra la Humanidad de NNUU (aprobación 1968, en vigencia 1970) - y la elaboración de otros ${ }^{27}$ que pudieran perseguir y punir delitos de nuevo cuño como las desapariciones masivas y sistemáticas que venían perpetrándose en la Argentina y varios países latinoamericanos (una Convención Internacional sobre Desaparición Forzada de Personas). ${ }^{28}$

Entre el último trimestre de 1979 y finales de 1981, y al compás de una serie de movimientos legislativos (leyes 22.062 y 22.068 ) y polí-

\footnotetext{
${ }^{26}$ Zolo, (2007): 43.

${ }^{27}$ En el acto del 24 de marzo de 1981 organizado por la CADHU Madrid, el jurista español Joaquín Ruiz Giménez Cortés manifestó que «ese tremendo nuevo instrumento de las desapariciones de los presos políticos tiene que ser denunciado y condenado por las NN.UU. Yo os digo... que las NN.UU. deben añadir a sus ya muchas condenas - no importa cuántas porque son gotas que golpean en la roca - una convención para acabar de una vez con las desapariciones políticas en todos los países del mundo». CADHU Madrid. «Libertad, Justicia y Democracia para Argentina, a cinco años del golpe militar», en Amorós, (2011): 387.

${ }^{28}$ Desde el Coloquio de París (enero 1981), el I y II Congresos Latinoamericanos de Familiares de Detenidos Desaparecidos (San José de Costa Rica y Caracas, enero y noviembre de 1981) y hasta el III Congreso de FEDEFAM (Caracas, junio 1982), los exiliados argentinos discutieron ponencias y documentos que volcaron finalmente en un proyecto de Convención Internacional sobre Desaparición Forzada de Personas. Este proyecto fue redactado por una comisión de juristas convocada por FEDEFAM en base a todos los aportes de los encuentros de 1981. Para un análisis pormenorizado de cuatro de los principales pre-proyectos (Héctor Faúndez Ledesma, catedrático de Derecho Internacional, Universidad Central de Venezuela; «Carta de Madrid» de la Asamblea Permanente por los Derechos Humanos; Victoria Abellán y Roberto Bergalli, profesores de Derecho de la Univ. de Barcelona) discutidos en el II Congreso de Caracas y del anteproyecto de Convención de FEDEFAM que fue analizado en la reunión de junio de 1982. Véase FundaLatin, (1982).
} 
ticos de la Junta militar ${ }^{29}$ que parecían ir en el sentido de pretender cerrar una etapa de la «guerra antisubversiva», decretando la clausura del «problema de los desaparecidos», los exiliados avanzaron en una doble vía.

Por un lado, la de hacer de la justicia un territorio donde no solo buscar protección de derechos y libertades y luchar por la verdad de las violaciones a los Derechos Humanos que seguían perpetrándose en la Argentina, sino también en el cual exigir castigo a los responsables de esos delitos.

Por el otro, la clara incardinación de este aún incierto horizonte de la justicia punitiva - por el que iban a trabajar de forma sostenida desde entonces hasta el final del «Proceso de Reorganización Nacional» y aún después- con la cuestión de los «desaparecidos», aquel delito que constituía el punto más alto del cuadro represivo y de violaciones a los Derechos Humanos ocurridas bajo el gobierno militar presidido por el general Jorge. R. Videla.

En este contexto, el trabajo de los exiliados se desplegó en varios frentes, a saber:

1. La tipificación de las desapariciones forzadas como crimen contra la Humanidad o crimen internacional de acción continuada y, por lo mismo imprescriptible y plausible de ser sometido a cierta jurisdicción penal universal ${ }^{30}$ por referencia a la doctrina de Núremberg $^{31}$;

\footnotetext{
${ }^{29}$ Más allá de las «leyes sobre desaparecidos», otros hitos que marcan los tempranos debates en torno a lo a las luchas por el «juicio y castigo a los culpables» son: 1. la visita de la CIDH a la Argentina y la publicación de su informe, 2. los testimonios de las sobrevivientes de la ESMA en la Asamblea Nacional francesa (octubre 1979) y los debates en torno a los «traslados», 3. las declaraciones de Ricardo Balbín en Madrid («No hay desaparecidos. Creo que están muertos» (La Nación, 13/4/1980)), 4. el recambio de la titularidad del ejecutivo castrense (Videla por Viola, 29/3/1981).

${ }^{30}$ En su propuesta para el Proyecto de Convención discutida en Caracas en noviembre de 1981, el abogado Roberto Bergalli (integrante de COSOFAM Barcelona) señalaba que la futura convención debía establecer «el tipo de delito que constituye la desaparición forzada e involuntaria de personas, cumplida por motivos políticos o religiosos. Su determinación justificará la inclusión de él en una convención internacional y la obligatoriedad del cumplimiento de sus cláusulas por todos los estados que adhieran. Bergalli, R. «Proyecto IV: Sugerencias en tono a una propuesta de Convención Internacional sobre la Desaparición Forzada o Involuntaria de Personas», en: FundaLatin, (1982): 29-30.

${ }^{31}$ En varios de los proyectos debatidos en Caracas incluido el del Foro de París presentado por Rodolfo Mattarollo aparecían menciones a la doctrina Núremberg. Mattarollo explica-
} 
2. La exploración de un nuevo régimen de prueba ${ }^{32}$ que permitiera punir a los responsables de un delito cometido en la clandestinidad y cuya responsabilidad era sistemáticamente negada por los agentes estatales;

3. El debate acerca de cuáles eran los tribunales más idóneos para el juzgamiento de los responsables de las detenciones-desapariciones: los tribunales argentinos de un futuro gobierno electo por el pueblo, un tribunal internacional ad hoc, ${ }^{33}$ una corte penal internacional a constituirse en el futuro;

4. La conveniencia de trabajar en la articulación de nuevos instrumentos jurídicos como una Convención Internacional en pos de ese objetivo punitivo ${ }^{34} \mathrm{o}$, en cambio, la posibilidad de utilizar los marcos normativos vigentes, sea del Derecho Internacional $\mathrm{Hu}$ manitario, sea de la legislación penal argentina. ${ }^{35}$

ba que las desapariciones forzadas constituían un crimen internacional: «traen como consecuencia la responsabilidad personal sin que se pueda invocar la excusa de actos de Estado, ni el deber de obediencia; la imprescriptibilidad y su carácter de derecho común; sus autores no pueden beneficiarse ni de amnistía ni del derecho de asilo. Además como fue muy claramente establecido por el tribunal de Núremberg no es posible invocar la no retroactividad de la ley penal en el caso de un crimen contra la humanidad». FundaLatin (1982): 6.

${ }^{32}$ En el proyecto de Convención de la APDH se planteaba la «presunción de responsabilidad» que en el caso de las desapariciones forzadas incluían: la del gobierno en cuya jurisdicción se hubiera producido la desaparición, si hubiese sido precedida de detención regular o de secuestro con sujeción a las siguientes condiciones. FundaLatin, (1982): 16-17.

${ }^{33}$ El debate sobre el «Núremberg» tuvo otras aristas. Roberto Bergalli si bien trabajó en pos de la Convención, se inclinaba por servirse de la legislación internacional o nacional vigente para perseguir a responsables de las actuales desapariciones en la Argentina. A su juicio, la lucha por la Convención introducía el problema de la retroactividad de las leyes penales y reincidía en el pecado original de la Justicia Penal Internacional: la de ser una «justicia de vencedores» o una especie de «justicia revolucionaria». Bergalli, Roberto, (1982), «Coloquio Internacional sobre los desaparecidos, en Resumen de Actualidad Argentina, Madrid, $\mathrm{n}^{\mathrm{O}}$ 57: 8 .

${ }^{34}$ El abogado Enrique Bacigalupo que participó del Coloquio de París no veía operativa la Convención como instrumento de justicia punitiva sobre las desapariciones. A su juicio, las leyes penales no eran retroactivas: «el problema de los desaparecidos no es un problema de futuro. Es un problema de pasado. No se trata de descubrir cómo sancionar hechos que todavía no se han cometido, sino de saber quiénes son los responsables de las muertes, de las torturas, de los robos, etc. que ya se han cometido [...] El derecho vigente es suficiente para hace justicia, siempre y cuando se quiera, claro está». Bacigalupo, Enrique, (1981), «Sobre exiliados y desaparecidos», en Resumen de Actualidad Argentina, Madrid, n 54, 37.

${ }^{35}$ El jurista Roberto Bergalli que participó del Coloquio de París y del Congreso de Caracas de noviembre de 1981 cuestionaba la necesidad de crear un derecho para juzgar a los 


\section{A manera de cierre}

En definitiva, mientras el cerco internacional a la Junta crecía y las resistencias interiores se hacían más firmes y extendidas, pero cuando aún no se atisbaba el «final de larga noche dictatorial» 36 la CADHU conmemoró en la Villa de Madrid el $5^{\circ}$ aniversario del golpe de Estado levantando la consigna «Libertad, Justicia y Democracia».

En marzo de 1981, la resistencia antidictatorial en el exilio $\rightarrow$ eco de esta voz resistente colectiva» del interior- proponía a la justicia como una de tres banderas del «tríptico ineludible sobre el que deb[ía] construirse el futuro argentino». ${ }^{37}$ Como planteaba contemporáneamente la CADHU México, «no podría existir una vida democrática y en libertad si no se esclarecen y castigan justamente los crímenes del terrorismo de Estado». ${ }^{38}$ Si la CIDH había recomendado a la Junta «enjuiciar y sancionar» a aquellas «autoridades públicas y a sus agentes» imputados en hechos represivos, contemporáneamente los exiliados convirtieron el «juzgamiento y castigo» en un mojón en su horizonte de lucha.

En un contexto en el que los llamados al «diálogo político» se desvelaban como cantos de sirena y las supuestas «aperturas democráticas» eran denunciadas como «recursos tácticos» ${ }^{39}$ que pretendían retardar el evidente resquebrajamiento del poder dictatorial imponiendo olvido e impunidad los exiliados plantearon dos líneas rojas.

La primera, que no podría haber «vigencia plena de la ley, el Estado de Derecho y la democracia» si se aceptaba un «pacto con el extermi-

responsables de las desapariciones forzadas en Argentina. A su juicio el delito de la desaparición forzada involucraba toda una serie de conductas dolosas contempladas en la legislación penal argentina y en la de otros países latinoamericanos, a saber: allanamiento de morada, privación ilegal de libertad, tortura, violación de correspondencia e incumplimiento del deber del funcionario público: «Ahí están los derechos penales nacionales vigentes que acogen sanciones para cada una de las violaciones en que se incurre cuando se hace «desaparecer» forzada e involuntariamente a las personas». Bergalli, Roberto, (1982), «Coloquio Internacional sobre los desaparecidos, en Resumen de Actualidad Argentina, Madrid, $n^{\circ} 57: 9$.

${ }^{36}$ CADHU Madrid. «Presentación de la CADHU: Acto: Libertad, Justicia y Democracia para Argentina. A cinco años del golpe militar», marzo 1981, en Amorós, (2011): 379

${ }^{37}$ CADHU México, «Aportes para descifrar la realidad argentina. Represión, economía, educación y salud en Argentina», febrero 1981, en Amorós, (2011): 356.

${ }^{38}$ CADHU México, «Aportes para descifrar la realidad argentina...», febrero 1981, en Amorós, (2011): 356.

${ }^{39}$ CADHU México, «Aportes para descifrar la realidad argentina...», febrero 1981, en Amorós, (2011): 356. 
nador». ${ }^{40} \mathrm{Si}$ los argentinos ansiaban la «paz»y la «reconciliación nacional para reconstruir el país y sus instituciones, dejando de lado los desencuentros secundarios que nos enfrentaron en el pasado con la fuerza de antagonismos irreconciliables, permitiendo el avance de los represores» ${ }^{41}$, aquellas no serían posibles «traficando» «el destino de los 30.0000 «desaparecidos», los presos políticos, los perseguidos, las comisiones internas y los delegados barridos de las fábricas, todas las secuelas de la acción dictatorial». ${ }^{42}$

La segunda, que frente a los intentos de «borrón y cuenta nueva»y las operaciones de «lavado de cara» del régimen», no había otro cauce para la lucha antidictatorial en el exilio que la memoria y la justicia o la memoria para la persecución y el castigo. Como reclamaba en Madrid Lidia Massaferro en marzo de 1981 y en presencia de Eduardo Galeano, Julio Cortázar y Rafael Alberti: «Memoria y cuenta del dolor del pueblo y de las víctimas directas. Memoria y cuenta de los asesinos, torturadores y explotadores. Memoria viva que se difunda en la justicia.» ${ }^{43}$

Porque aunque la agenda del cambio institucional fuera aún incierta, confiada en la creciente «unidad en la lucha antidictatorial en Argentina», ${ }^{44}$ Massaferro se animaba a anunciar que más temprano que tarde: «Habrá Núremberg, habrá investigación, habrá reparación de tanto escarnio. La potencialidad de un pueblo que no han conseguido castrar lo garantiza». ${ }^{45}$

Como expresaba en la Villa de Madrid la directiva de la CADHU, «la alborada popular tendrá ineluctablemente un punto de comienzo: «el juzgamiento y castigo de todo aquello que no será olvidado». ${ }^{46}$

\footnotetext{
${ }^{40}$ CADHU Madrid. «Intervención de Lidia Massaferro: Acto: Libertad, Justicia y Democracia para Argentina. A cinco años del golpe militar», marzo 1981, en Amorós, (2011): 380 .

${ }^{41}$ CADHU Madrid. «Presentación de la CADHU...,en Amorós, (2011): 378

${ }^{42}$ CADHU Madrid. «Presentación de la CADHU...,en Amorós, (2011): 378

${ }^{43}$ CADHU Madrid. «Intervención de Lidia Massaferro, en Amorós, (2011): 381.

${ }^{44}$ CADHU Madrid. «Intervención de Lidia Massaferro, en Amorós, (2011): 380.

${ }^{45}$ CADHU Madrid. «Intervención de Lidia, en Amorós, (2011): 381.

${ }^{46}$ CADHU Madrid. «Presentación de la CADHU..., marzo 1981, en Amorós, (2011): 379.
} 


\section{Referencias bibliográficas}

ACUÑA, Carlos et al, (1995), Juicio, castigos y memorias: derechos bumanos y justicia en la politica Argentina. Buenos Aires: Nueva Visión.

AMNISTÍA INTERNACIONAL, (1977), Informe de una misión de Amnistía internacional a la República Argentina, 6-15/11/1976. Barcelona: Blume.

ALONSO, Luciano, (2015), «Redes y dimensiones espaciales en la movilización por los derechos humanos en Argentina», en Avances del Cesor, año XII, vol. XII, no 12, primer semestre: 117-139. Disponible en http://web2.rosario-conicet.gov.ar/ojs/index.php/AvancesCesor/index [último acceso: 2/5/2017]

AMORÓS, Mario (coord.), (2011), Argentina en el Archivo de IEPALA (1976-1983). Madrid: IEPALA.

BOHOVSLAVSKY, Juan Pablo (ed.), (2015), ¿Usted también doctor? Complicidad de jueces, fiscales y abogados durante la dictadura. Buenos Aires: Siglo XXI.

CADHU, (2014), Argentina. Proceso al genocidio. Buenos Aires: Colihue.

CAMARASA, Jorge, FELICE, Rubén y Daniel GONZÁLEZ, (1985), El juicio, proceso al horror: de la recuperación democrática a la sentencia. Buenos Aires: Sudamericana.

CHAMA, Mauricio, (2016), Compromiso politico y labor profesional: estudios sobre psicólogos y abogados en los primeros setenta. La Plata: UNLPFAHCE

CIANCAGLINI, Sergio y GRANOVSKY, Martín, (1995), Nada más que la verdad: el juicio a las Juntas. La guerra sucia desde el golpe hasta las autocriticas militares. Buenos Aires: Planeta.

CIDH, (1980), Informe sobre la situación de los Derechos Humanos en Argentina. Washington: O.E.A, Disponible en http://desaparecidos.org/ nuncamas/web/document/internac/cidh79/index.htm, [último acceso $28 / 10 / 2016]$.

CRENZEL, Emilio, (2008), La historia politica del Nunca Más. La memoria de las desapariciones en la Argentina. Buenos Aires: Siglo XXI.

CRENZEL, Emilio, (2015), «Ideas y estrategias de justicia ante la violencia política y las violaciones a los derechos humanos en la transición política en Argentina (1982-1983)», en FELD, Claudia y FRANCO, Marina (dirs.), Democracia, hora cero. Actores, politicas y debates 
en los inicios de la postdictadura. Buenos Aires: FCE: 81-114.

FELD, Claudia, (2002), Del estrado a la pantalla: las imágenes del juicio a los ex comandantes en Argentina. Madrid: Siglo XXI.

FELD, Claudia, (2010), «La representación de los desaparecidos en la prensa de la transición: «el show del horror»», en CRENZEL, Emilio (coord.), Los desaparecidos en la Argentina. Memorias, representaciones e ideas (1983-2008). Buenos Aires: Biblos: 25-41.

FELD, Claudia y FRANCO, Marina, (2015), «Democracia y derechos humanos en 1984, ¿hora cero?», en FELD, C. y FRANCO, M, Democracia, hora cero. Actores, politicas y debates en los inicios de la postdictadura. Buenos Aires: FCE: 384-400.

FRANCO, Marina, (2011), «A «solidaridade» ante os exílios dos anos 1970: reflexoes a partir do caso dos argentinos en França», en QUADRAT, Samantha, Caminhos Cruzados. História e memória dos exilios latino-americanos no século $X X$. Río de Janeiro: FGV: 91115.

FUNDALATIN, (1982), Los desaparecidos. Propuestas para un proyecto de Convención Internacional contra las desapariciones forzadas. Caracas: FUNDALATIN.

GALANTE, Diego, (2014), El «Juicio a las Juntas Militares»: derechos bumanos, memoria y ciudadanía en la argentina (1983-2013). Tesis doctoral, FSOC- UBA.

GANDULFO, Juan, (2014), El caso de las tumbas N.N. en Grand Bourg. La justicia y los organismos de derechos humanos en la transición a la democracia. Tesis de Magister, IDES-UNGS.

GARZÓN MACEDA, Lucio, (2006), «Testimonio. La primera derrota de la dictadura en el campo internacional», en QUIROGA, H. y C. TCACH (comps.), Argentina, 1976-2006. Entre la sombra de la dictadura y el futuro de la democracia. Rosario: Homo Sapiens.

GONZÁLEZ BOMBAL, Inés, (1995), «Nunca más: el juicio más allá de los estrados», en AA.VV., Juicio, castigos y memorias. Derechos humanos y justicia en la politica argentina. Buenos Aires: Nueva Visión: 193-216.

GONZALEZ BOMBAL, Inés y SONDEREGUER, María, (1987), «Derechos humanos y democracia», en JELIN, Elizabeth (ed.), Movimientos sociales y democracia emergente. Buenos Aires: CEAL: 85-112. 
GROISMAN, Enrique, (1987), La Corte Suprema de Justicia durante la dictadura (1976-1983). Buenos Aires: CISEA.

JELIN, Elizabeth, (1995), «La política de la memoria: el movimiento de Derechos Humanos y la construcción democrática en la Argentina, en: AA.VV., Juicio, castigos y memorias: derechos humanos y justicia en la politica argentina. Buenos Aires: Nueva Visión: 103145.

JELIN, Elizabeth, (2006), «La justicia después del juicio: legados y desafíos en la Argentina postdictatorial», en Tribuna Americana. Revista de reflexión politica, $n^{0}$ 6, primer semestre: 35-49.

JELIN, Elizabeth, (2015), «Certezas, incertidumbres y búsquedas: el movimiento de derechos humanos en la transición, en FELD, C y FRANCO, M. (dirs.), Democracia, hora cero. Actores, politicas y debates en los inicios de la postdictadura. Buenos Aires: FCE: 195-223

LEIS, Héctor, (1989), El movimiento por los derechos humanos y la politica argentina. Buenos Aires: CEAL, 2 vols.

MALAMUD GOTI, Jaime, (2000), Terror y justicia en la Argentina: responsabilidad y democracia después de los juicios al terrorismo de Estado. Buenos Aires: Ediciones de la Flor.

NINO, Carlos, (1997). Juicio al mal absoluto. Buenos Aires: Emecé.

QUIROGA, Hugo (1996), «La verdad de la justicia y la verdad de la política. Los derechos humanos en la dictadura y en la democracia», en QUIROGA, Hugo y TCACH, César (comps.), A veinte años del golpe. Con memoria democrática. Rosario: Homo Sapiens: 67-86.

SARRABYROUSE OLIVEIRA, María, (2011), Poder Judicial y dictadura. El caso de la morgue. Buenos Aires: CELS y del Puerto.

SIKKINK, Kathryn, (2011), The justice cascade: how human rights prosecutions are changing world politics. New York: W. W. Norton \& Company

VEZZETTI, Hugo, (2002), Pasado y presente: Guerra, dictadura y sociedad en la Argentina. Buenos Aires: Siglo XXI.

VILLALTA, Carla, (2012), Entregas y secuestros. El rol del Estado en la apropiación de niños. Buenos Aires: Ediciones del Puerto.

ZOLO, Danilo, (2007), La justicia de los vencedores. De Núremberg a Bagdag. Buenos Aires: Edhasa. 